During 1888 there were eighteen instances of this, in which the beginnings of the attendant magnetic perturbations, as shown by the self-recording magnetograph, were so abrupt that it was possible by this means to determine the time of the revolution of the sun, the average period thus found being twenty-six days and eight hours.

This behaviour of auroras and magnetic storins indicates that any solar disturbance which may originate them has this power during a limited portion only of its transit across the earthward side of the sun. From April r 886 to April 1889 inclusive, there were in this country 188 such characteristic outbreaks of the atrora. In twenty-six, observations were lacking ; but in the remaining 162 , in every instance, bright faculæ with or without dark spots are known to have been located upon the sun's eastern limb appearing by rotation. In those instances in wlich a disturbance appearing by rotation failed to originate an aurora, there was, as a rule, an increase in the number of stations reporting thunderstorms. Indeed, at such times there was always an increase of thunderstorms, although the aurora when at its height not unfrequently seemed to take their place, causing a temporary decrease. From this it follows that the appearance upon the sun by rotation of spots or faculæ is a condition upon which the appearance of the aurora or increase of thunderstorms to some extent depends.

Lyons, New York, July i7.

\section{Do Animals Count?}

Having studied Sir J. Lubbock's interesting book, I remembered a fact observed by me, which, though it is not conclusive, seems worth mentionin. I was amised some years ago to observe the feeding of the young in a sparrow-house near an upper window of my house. The old sparrow alighted upon the small veran la of the sparrow-house with four living cankerworms in his beak. Then the four young ones put out their heads, with the customary noise, and were fed each with a caterpillar. The sparrow went off, and returned after a while again with four living cankerworms in his beak, which were disposed of in the same manner. I was so interested and pleased with the process that I watched it for some time and during the following days.

A fact which I have not seen noticed here in the extensive sparrow literature, is that for a number of years sparrows begin to build nests of dry grass and hay at the top of high trees. The first I saw were large irregular balls placed on the tripod of twigs. The entrance was on the inner side ncar the lower end of the balls. Last year, I observed another form of the nests. A strong rope formed of dry grass, as thick as a man's wrist and as Iong as the forearm, is fastened only with the upper end to strong branches at the top of high trees. The rope's end has a rather large ovoid shape with the entrance to the inside near the end. Of such nests I saw last winter about a dozen on the elms here in Main Street, near the College grounds, and similar ones in I'utnam $A$ venue and other streets. A long pole near my house strongly covered by a vine (Celastrus scandens) had such a nest for three years, used every year.

In the sparrow-houses around my lodging the sparrows stay throughout the winter; commonly one male and three females in every house, till in spring the superfluous females are turned out.

Museum of Comparative Zoology, Cambridge, Mass. July 15.

\section{The "Hatchery" of the Sun-fish.}

THE fact that the "sun-fish" of the American lakes and streams prepares a place for the deposit of its eggs and guards them till hat ched is widely known. Certainly is has long been known and is recorded in all recent American works on fishes. The first detailed statement of its nidification I know of was published by Dr. John D. Godman, in his "Rambles of a Naturalist," about 1830, and is reprinted with the third and succeeding editions of his "American Natural History," published in 1836 , \&c.

Another quite full account of its nest building and care of the eggs was published, with an illustration, by the late Prof. L. Agassiz in the Proceedings of the American Academy of Arts and Sciences (vol. iii. pp. 329, 330, I857). Bat the accounts of Godman and Agassiz, as well as all others, and my own observations, fail to agree with those recorded in NATURE (June 27, p. 202). The sun-fish, generally at least, simply clears a subcircular area whose diameter is usually about two or three times its own length, and therein the female deposits her eggs. It has generally been assumed that she alone or she and the male in turn guards the nest. The idea, however, is only the result of analogy from the observation of the higher vertebrates. It is quite likely that the male fish is usually the guardian of the nest, as in the case of the Gasterosteids, Cichlids, and Silurids.

It should be added that the American sun-fish, although called in some places roach and bream, is not at all related to the English fishes so named, but is the representative of a family (Centrarchide) peculiar to and quite characteristic of North America. This family is exemplified by about forty species, referred to ten or eleven genera. The only species observed in the Adirondack region is the Eupomotis gibbosus, generally known to European naturalists as Pomatis vilugaris or auritus. The family is closely related to the Percids, and is indeed considered to form a part of the latter by many naturalists, and has nothing to do with the Cyprinids, to which the roach and bream belong.

Washington, July i 7 .

THEO. GILL.

\section{Centrifugal Force and D'Alembert's Principle.}

I agrce so cordially with the greater part of Prof. Minchin's address to the Association for the Improvement of Geometrical 'Teaching, delivered on January $19, \mathbf{I} 889$, and reported in NATURE of June $6, p$. I26, that I feel the more induced to enter a protest against his remarks on the subject of "centrifugal force."

I admit that the name is not well chosen, and is often mis. understood, but I contend that we want a name for certain forces which are now called centrifugal, and which, until a better name be suggested, we can do no better than to continue to call by that name.

If a train, passing round a curve at too great a rate, tears the rails from the sleepers, we want a name for the force producing this effect. When a train, running over a horizontal girder bridge, produces a deflection greater than that due to its weight, we want a name for the force producing this extra strain.

The popular mistake is in regarding centrifugal force as a force imparted to a body whose motion is being deflected, instead of being imparted by such a body.

When a wet mop is trundled, for example, the water docs not fly from it owing to centrifugal force, but owing to want of sufficient centripetal force to keep it back.

Prof. Minchin says :- "If we imagine a stone to be attachel to an elastic string, one end of which is tied to the hand, while the stone is projected vertically upwards, the hand would experience an upreard pull. Are we thence to conclude that the stone is continually acted on by an upivard force?"

From this illustration Prof. Minchin obviously objects to the term "centrifugal force" as meaning a force imparted to the body whose motion is being deflected. In this he is certainly right, but this is no objection against its legitimate use as a force imparted by such a tody.

Clerk Maxwell ("Matter and Motion," p. 97), says that "in some popular treatises centripetal and centrifingal forces are de. scribed as opposing and balancing each other. But they are merely different aspects of the sane stress." Just so. But because two classes of forces are different aspects of the same stress, why, if sufficiently common and important, should they not have distinctive names given them?

What I understand by centrifugal force is the reaction against a force deflecting a body's motion.

Knowing the objections which have been raised to the use of the term centrifugal as denoting such forces, I have endeavoured to find some unobjectionable equivalent for it. For cintripetal forie (which, strangely enough, is not generally objected to), I have found what seems to me a fair equivalent, viz. normal force, defininer force as normal when it produces deflection only, and tangential when it produces change of rate only, bit I have never been able to find a better name than centrifugal for the reaction against normal forces.

Prof. Minchin traces back what he considers to be the "fallacy" of centrifugal force to D'Alember's principle, to which he objects as "unnatural and unnecessary." I do not think he will get many to agree with him in this view. The hypothetical reversal of the resultant forces in D'Alembert's principle may be unnecessary in the sense that we can do without it; but as it 